\title{
Mediastinal hemangioma: Successful treatment by alpha-2a interferon and postchemotherapy resection
}

\author{
Pankaj Kumar, FRCS, ${ }^{a}$ Ian Judson, FRCP, ${ }^{\mathrm{b}}$ Andrew G. Nicholson, DM, ${ }^{\mathrm{c}}$ and George Ladas, FETCS, ${ }^{\mathrm{a}}$ \\ London, United Kingdom
}

$\mathrm{A}$

33-year-old nonsmoker had an 8-month history of hemoptysis. He was otherwise well, with normal hematologic and biochemical indices, and his medical history was unremarkable. Fiberoptic bronchoscopy elsewhere showed external compression of the airway, consistent with a mediastinal mass, but no endobronchial lesions. Biopsy specimens showed capillary proliferation in the subepithelial stroma but no cytologic features of malignancy. The possibility of a benign or low-grade vascular neoplasm was raised. After the biopsy, the patient had a massive hemoptysis necessitating blood transfusion. Subsequent contrast computed tomographic and magnetic resonance imaging scans demonstrated an extensive mediastinal mass of high vascularity, which extended from above the level of the azygos arch to the left atrium inferiorly. The tumor also encased the carina, esophagus, and several major blood vessels within the mediastinum (Figure $1, A$ and $B$ ). On examination with a rigid bronchoscope, there was profuse arterial bleeding at the biopsy site from the left main bronchus and evidence of further recent bleeding distally. Hemostasis was secured by cauterizing the arterial bleeding point with a diathermy loop. Because of uncertainty over the histologic diagnosis and degree of malignancy, cervical mediastinoscopy was also undertaken, which showed paratracheal and subcarinal tissues infiltrated by a vascular mass containing several large tortuous arteries. Biopsy showed similar features to the bronchial biopsy, with lobules of cytologically benign capillaries infiltrating mediastinal soft tissues. A vascular phenotype was confirmed by positive immunohistochemical staining for CD34 and factor 8, and a diagnosis of capillary hemangioma was made (Figure 2, A).

Surgical resection was considered inappropriate because of diffuse mediastinal infiltration precluding complete resection,

From the Departments of Thoracic Surgery ${ }^{\mathrm{a}}$ and Histopathology, ${ }^{\mathrm{c}}$ Royal Brompton Hospital, London, and Department of Clinical Pharmacology, Royal Marsden Hospital, London, United Kingdom.

Received for publication Nov 24, 2001; accepted for publication Dec 10, 2001

Address for reprints: Mr G. Ladas, Consultant Thoracic Surgeon, Royal Brompton Hospital, Sydney Street, London, SW3 6NP, United Kingdom (E-mail: g.ladas@rbh.nthames.nhs.uk).

J Thorac Cardiovasc Surg 2002;124:404-6

Copyright (C) 2002 by The American Association for Thoracic Surgery

$0022-5223 / 2002 \$ 35.00+0 \quad \mathbf{1 2 / 5 4 / 1 2 2 5 4 0}$

doi: $10.1067 / \mathrm{mtc} .2002 .122540$ and he was treated with recombinant alpha-2a interferon (3 megaunits given subcutaneously 3 times per week) for 6 months. This led to significant symptomatic benefit, and a second computed tomographic scan demonstrated marked reduction in tumor bulk with only a small residual mass in the subcarinal area. A complete resection was now considered feasible. Another bronchoscopic examination showed normal bronchial mucosa. A right posterolateral thoracotomy was used for access. At thoracotomy, a 4-cm diameter, markedly fibrotic, residual mass still containing tortuous arteries up to $5 \mathrm{~mm}$ in diameter was seen. The mass extended from the right side of the trachea to the subcarinal region. The tumor was resected by sharp dissection, with care taken to ligate individual vessels before dividing them. Surgically, a complete resection was possible, and microscopically, the mass consisted of an abundance of thick-walled blood vessels with the vessels lying within dense fibrous stroma (Figure $2, B$ ). The cellular capillary proliferation was no longer present. The patient remains symptom-free and disease-free 18 months after resection.

\section{Discussion}

Tumors of vascular origin usually appear in childhood. Common locations include subcutaneous tissue, liver, bone, central nervous system, and spleen. Isolated mediastinal localization is rare and accounts for fewer than $2 \%$ of all mediastinal tumors. ${ }^{1,2}$ Vascular tumors comprise a wide spectrum of histopathologic entities ranging from benign hemangiomas, through low-grade malignant tumors such as capillary hemangiomas, up to overtly malignant angiosarcomas. ${ }^{3}$

Symptoms in patients with mediastinal hemangioma are related to compression or invasion of adjacent structures and may include symptoms of airway obstruction or dysphagia. Other rare presentations include superior vena cava obstruction, vocal cord paralysis, spontaneous hemothorax, or significant hemoptysis that may even require blood transfusion, as described in this case. ${ }^{4}$ Complete surgical resection remains the optimal treatment. ${ }^{3,4}$ but resection is considered extremely hazardous in patients with extensive involvement of mediastinal structures. Nevertheless, even incomplete resection has been advocated by some authors. ${ }^{2}$

Alpha-2a interferon is a highly purified recombinant DNA product and is a potent angiogenesis inhibitor that acts by blocking the action of basic fibroblast growth factor. In the proliferative phase, hemangiomas are characterized by endothelial cell migration and proliferation, and basic fibroblast growth factor is a major stimulus for this proliferation. It is therefore believed that alpha-2a interferon inhibits endothelial cell proliferation by blocking the actions of basic fibroblast growth 

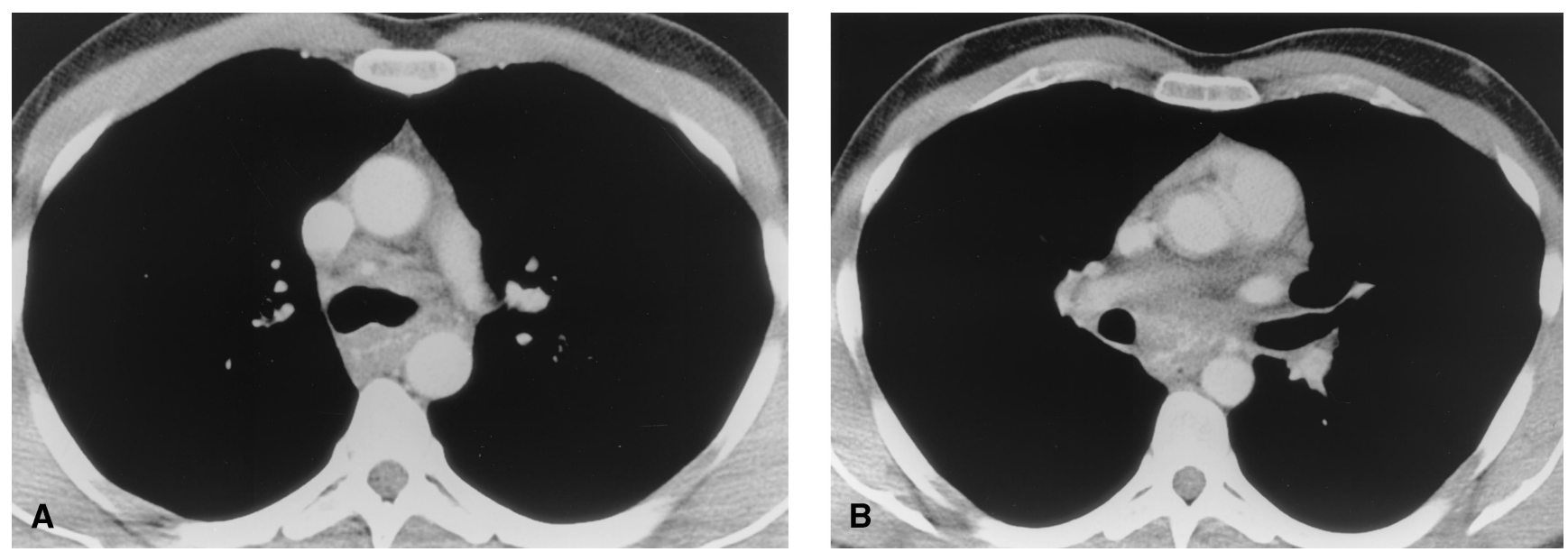

Figure 1. A and B, Computed tomographic scans of the chest showing extensive soft tissue mass encasing the trachea at the bifurcation and extending to the subcarinal area abutting the adjacent structures. Note the large blood vessels present within the soft tissue mass.
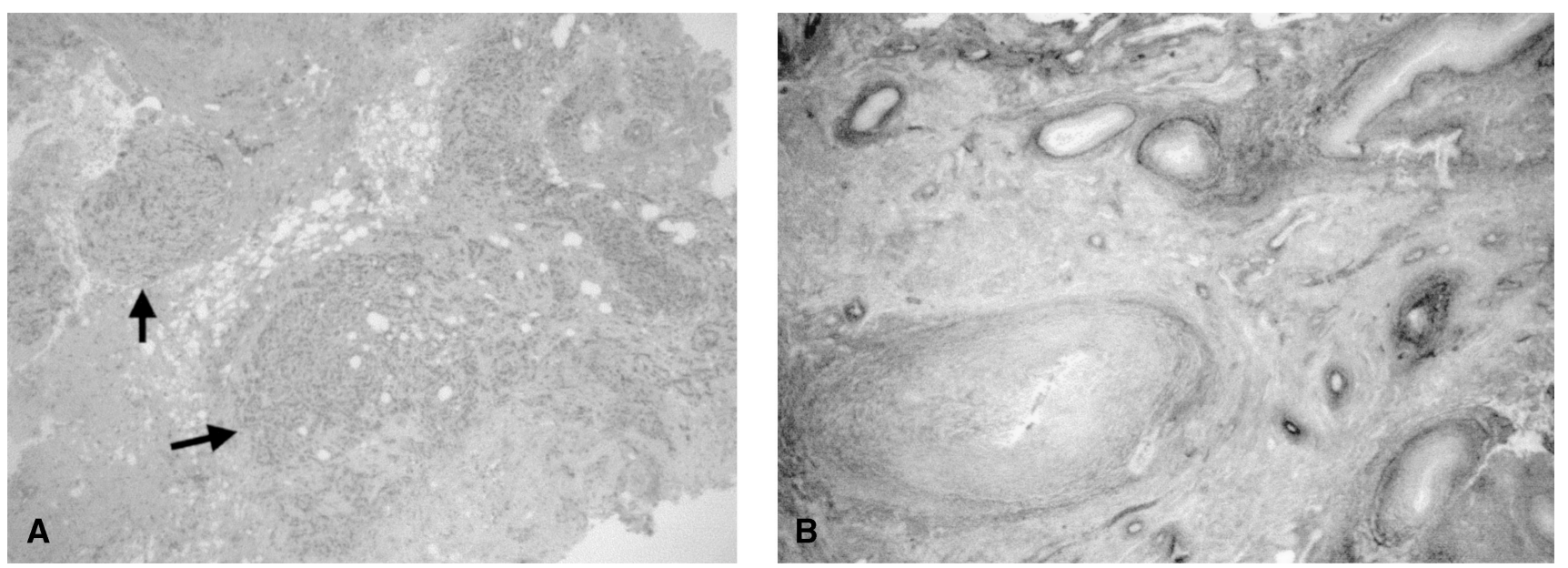

Figure 2. A, A mediastinal biopsy shows lobules of proliferating capillaries (arrows) infiltrating soft tissues, features characteristic of a hemangioma (hematoxylin and eosin stain; original magnification $\times 40$ ). $B, A$ section from the postchemotherapy resection specimen shows abundant tortuous feeder vessels only, lying within fibrous stroma. The vessels show prominent intimal fibrosis (elastic van Gieson stain; original magnification $\times 20$ ).

factor, ${ }^{5}$ and there is considerable experience with its use in children with hemangiomas at different sites including lifethreatening airway hemangioma. ${ }^{6}$

However, very little experience with alpha-2a interferon has been reported in adults, especially relating to mediastinal hemangiomas, and this case documents both a significant clinical response in this age group and a reduction of tumor bulk to a degree that enabled complete resection of a tumor initially considered inoperable. However, although alpha-2a interferon led to marked symptomatic benefit without any side effects in this case, neurologic, cardiac, and visual side effects are frequently reported in children. ${ }^{6}$
It is also interesting to note the change in tumor morphology after chemotherapy, with an absence of the capillary proliferation seen on the initial bronchoscopic and mediastinal biopsies and replacement by dense fibrosis, while the larger feeding vessels remained. This suggests that inhibition of basic fibroblast growth factor leads to preferential regression or inhibition of the endothelial cells in the areas of capillary proliferation.

In conclusion, use of alpha-2a interferon may represent a significant step forward in the management of such vascular tumors, especially in situations in which the tumor is initially considered to be inoperable. 


\section{References}

1. Cohen AJ, Thompson L, Edwards FH, Bellamy RF. Primary cysts and tumors of the mediastinum. Ann Thorac Surg. 1991;51:378-86.

2. Cohen AJ, Sbasching L, Hochholzer F, Lough C, Albus RA. Mediastinal hemangiomas. Ann Thorac Surg. 1987;43:656-9.

3. Toursarkissian B, O'Connor W, Dillon ML. Mediastinal epithelioid hemangioendothelioma. Ann Thorac Surg. 1990;49:680-5.
4. Mineo TC, Biancari F, Cristino B, D'Andrea VD. Benign vascular tumors of the mediastinum: presentation of three cases and review of literature. Thorac Cardiovasc Surg. 1995;43:361-4.

5. Folkman J. Successful treatment of angiogenic disease. N Engl J Med. 1989;320:1211-2.

6. Ohlms LA, Jopnes DT, McGill TJI, Healy GB. Interferon alpha-2a therapy for airway hemangioma. Acta Otol Rhinol Laryngol. 1994; 103:1 